\title{
Toughness of Railroad Concrete Crossties with Holes and Web Openings
}

\author{
Erosha K. Gamage ${ }^{1}$, Sakdirat Kaewunruen ${ }^{1,2, *}$, Alex M. Remennikov ${ }^{3}$ and Tetsuya Ishida ${ }^{4}$ \\ 1 Department of Civil Engineering, School of Engineering, The University of Birmingham, \\ Edgbaston B15 2TT, UK; EBK415@student.bham.ac.uk \\ 2 Birmingham Centre for Railway Research and Education, School of Engineering, \\ The University of Birmingham, Edgbaston B15 2TT, UK \\ 3 School of Civil, Mining, and Environmental Engineering, University of Wollongong, Northfield Ave, \\ Wollongong, NSW 2522, Australia; alexrem@uow.edu.au \\ 4 Concrete Laboratory, Department of Civil Engineering, University of Tokyo, 7 Chome-3-1 Hongo, Bunkyo, \\ Tokyo 113-8656, Japan; tetsuya.ishida@civil.t.u-tokyo.ac.jp \\ * Correspondence: s.kaewunruen@bham.ac.uk; Tel.: +44-121-414-2670
}

Academic Editors: Higinio González Jorge and Pedro Arias-Sánchez

Received: 30 June 2016; Accepted: 6 January 2017; Published: 11 January 2017

\begin{abstract}
Prestressed concrete sleepers (or railroad ties) are principally designed in order to carry wheel loads from the rails to the ground of railway tracks, as well as to secure rail gauge for safe train travels. Their design takes into account static and dynamic loading conditions. In spite of prestressed concrete crossties being most commonly used in railway tracks, there have always been many demands from rail engineers to improve the serviceability and functionality of concrete crossties. For example, signaling, fiber optic, equipment cables are often damaged either by ballast corners or by the tamping machine. There has been a need to re-design concrete crossties to incorporate cables internally so that they would not experience detrimental or harsh environments. Also, many concrete crossties need a retrofit for an automatic train control device and similar signaling equipment. In contrast, the effects of holes and web openings on the structural capacity of concrete crossties have not been thoroughly investigated. This paper accordingly highlights the experimental investigations into the effect of holes and web openings on the toughness and ductility of concrete crossties. The key outcome of this research is to enable a better decision making process for retrofitting prestressed concrete crossties with holes and web openings in practice.
\end{abstract}

Keywords: concrete sleeper; crosstie; design standard; holes; web opening; railway infrastructure; static performance

\section{Introduction}

Railroad is a standout method amongst the most essential and broadly utilized means of transportation, conveying cargo, passengers, minerals, grains, and so forth. Railway prestressed concrete crossties have been utilized in the railway industry for over 50 years [1-3]. The railroad ties (called 'railway sleepers') are a main part of railway track structures. The crossties can be made of timber, concrete, steel or other engineered materials [4]. Concrete crossties were initially introduced many decades ago and at present have been introduced almost everywhere in the world. Their major role is to distribute loads from the rail foot to the underlying ballast bed. Railroad track structures often experience impact loading conditions due to wheel/rail interactions associated with abnormalities in either a wheel or a rail [1]. In addition, railroad track components are often being modified at construction sites to fit with signaling gears, cables, and additional train derailment protections, such as guard rails, check rails, earthquake protection rails, etc. The practical guidelines for crosstie 
retrofit have not been well established and many attempts were carried out based on trial and error. Despite being a common task in construction sites, the behavior of holes and web openings on concrete crossties has not been well documented in open literature. A review of existing standard design codes (e.g., EN13230-2, AREMA C4, AS1095.14, or ACI) reveals that there is a necessity to investigate such important aspects [2]. In this manner, it is important to ensure that concrete crossties can be safely retrofitted and modified for add-on fixtures in practice. Also, note that a key performance criterion in existing design principles (i.e., limit states design concept and permissible stress design principle) still relies on ultimate static performance. The ultimate capacity of concrete crossties indicates many structural features with respect to the dynamic and service performance of crossties. The emphasis of this study has been placed on the experimental studies into energy toughness of the crossties with holes and web openings. This characteristic, which is not well known, is an important factor in the structural design of concrete crossties, especially for the failure mode identification at ultimate state. The toughness characteristic has a correlation with the residual performance of sleepers under dynamic and impact loading conditions [3]. The insight into these behaviors will not only improve the safety and reliability of railway infrastructure, but will enhance the structural safety of other concrete structures.

\section{Experimental Evaluation}

The holes and web openings are generated using a high-speed coring machine on full-scale crossties. Common types of holes and web openings in practice have been carried out, including the vertical and longitudinal holes as well as the lateral through hole, as illustrated in Figure 1, in order to accompany other systems' needs as demonstrated in Figure 2. For practicality, $42 \mathrm{~mm}$ diameter holes have been cored in a similar manner as in an actual construction. Then, they are tested under the prescribed static testing condition in order to identify the comparable and repeatable residual energy toughness [5]. The benchmarking test method, in accordance with European Standard EN 13230-2, has been adopted for this study [2]. The static setup includes three point bending tests with the span length of $600 \mathrm{~mm}$. Through the static tests, the load carrying capacity is plotted against railseat deflection. The fracture toughness can subsequently be identified by the integration (area under the curve) of the load-deflection relationship [6]. The comparative index is a ratio between the toughness with and without holes.

In general, the full load-deflection curve can be found in Figure 3. The first stage of the curve is the elastic stage when materials behave linearly in an elastic range. Then, the nonlinear behavior takes place when the principal stress reaches the proportional yield stress and the materials make use of the nonlinear portion of the strength. Until the structural member reaches ultimate capacity or stability failure, the nonlinear portion dominates. At the ultimate point, the load-deflection curve drops to a certain extent due to the crushing and the spalling of concrete. Then, yielding and a later snap of high strength strands cause a strength drop in the moment-deflection curve. The strength beyond this ultimate capacity, if the member is further loaded, is referred to as the residual fracture toughness in the post failure mechanism. The post failure mechanism can be clearly seen in Figure 3. It exhibits that the strands still provide the strength hardening effects to the residual load carrying capacity and the energy absorption mechanism until they reach the rupture capacity. The hardening effect is significant when more tendons remain and the effect decreases as the remaining number of tendons diminishes $[7,8]$.

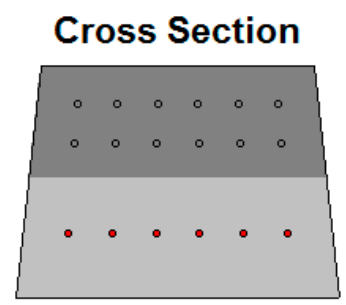

(a)

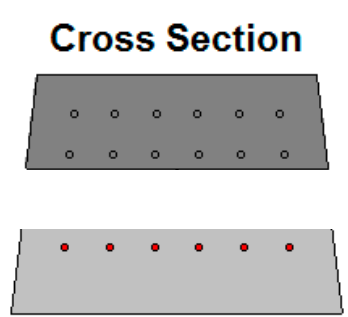

(b)

Figure 1. Cont. 


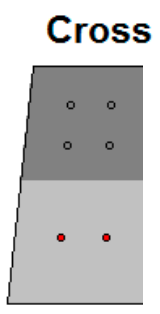

(c)

\section{Cross Section}

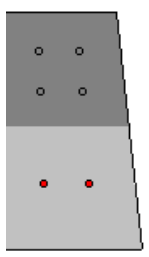

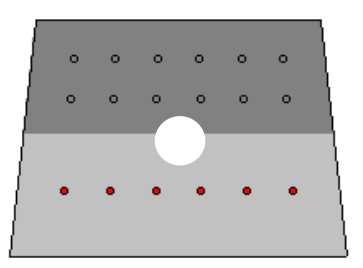

(d)

Figure 1. Web opening and holes in crossties in practice: (a) Full cross section of a traditional standard-gauge railway concrete crosstie; (b) Web Opening (or transverse hole); (c) Vertical hole; (d) Longitudinal or through hole. These holes are often installed after construction to accommodate various needs, such as cables, additional bolts, a bracing system, lateral or third rail fixtures, etc. The position of the hole is often at the middle between the edge of the rail and the sleeper end (with reduction to about half of the maximum of the shear force action). No steel reinforcement has been damaged from these holes and web openings. The standard-gauge crossties $\left(0.285 \times 0.175 \times 2.5 \mathrm{~m}^{3}\right)$ used as specimens were manufactured in the same bed under ISO9001 Quality Standard with material deviation less than $2 \%$. Two specimens were used for each case of hole and web opening. Its characteristic positive bending moment at railseat (25t axle load) as per EN13230-6 is about $34 \mathrm{kN} \cdot \mathrm{m}$ (excluding accidental loading).

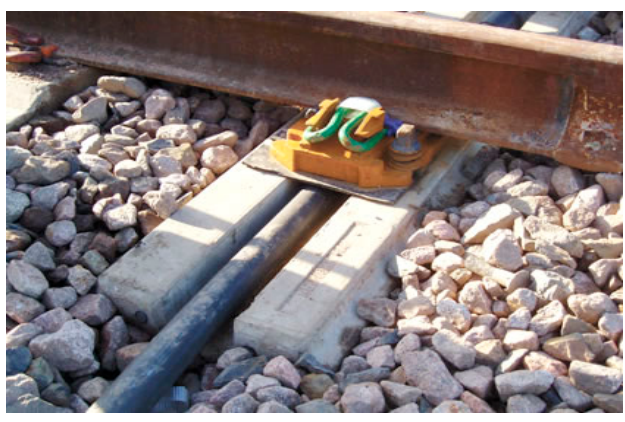

(a)

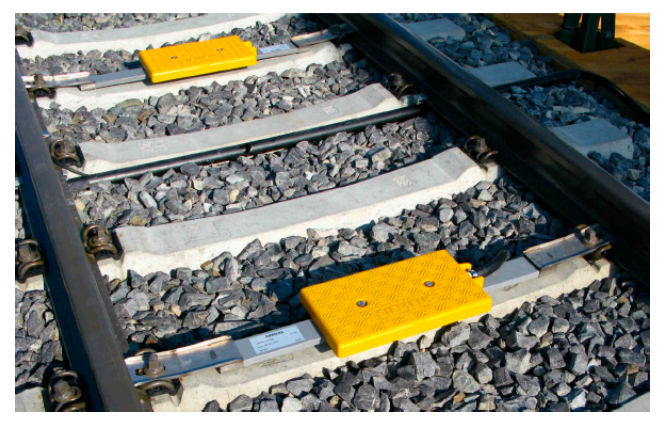

(b)

Figure 2. Needs for modification to suit cables and pipes (a); and advanced signaling systems (b).

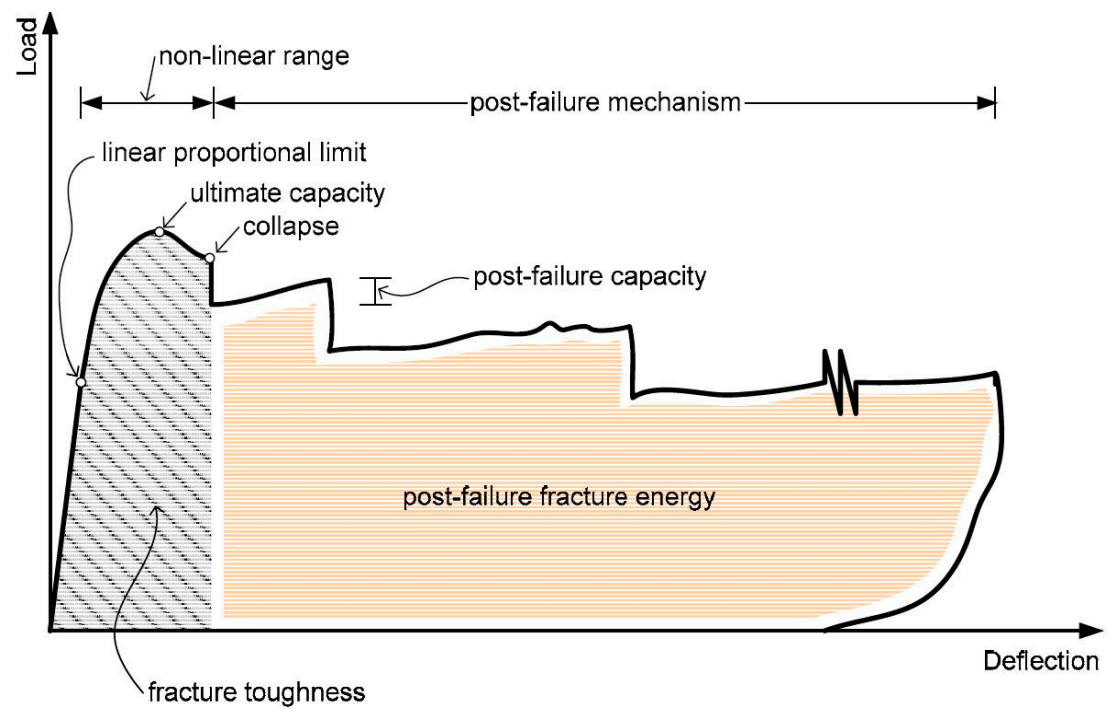

Figure 3. A schematic full load-deflection curve of a structural member, representing energy toughness of the member. The toughness is a fundamental characteristic of the structural or mechanical component in compliance with the 'conservation of energy' principle. 


\section{Results}

The holes and web openings are established on full-scale concrete crossties using a high-speed diamond-coring machine in order to minimize micro cracking in concrete. Common types of holes and web openings in practice are about $40 \mathrm{~mm}$ in diameter, which is sufficient for fitting industrial cables and rods. Critical locations (such as along the shear stress path, at position right under the maximum bending moment, and a location for industry purposes) have been chosen based on earlier numerical studies using a finite element package ABAQUS [9-12]. The static tests have been carried out in accordance with BS EN13230 for benchmarking purposes [5]. In this technical note, we focus on experimental investigations into structural toughness, which is an important characteristic to predict failure for ultimate and damageability limit states. The toughness has a strong correlation to the residual dynamic performance of the sleepers [11]. Under the ultimate limit state, it is clear that the damage under static loading must be considered. However, it is important to note that low cycle fatigue failure often occurs in a similar manner. Importantly, the existing EN13230-2 cannot adequately inform engineers of what type of failure mode they could predict from the initial design and cannot inform maintenance engineers of what will happen if the operational condition is changed. This importance motivates this experimental study.

The experimental results reveal a very interesting behavior of the crossties with holes and web openings. Table 1 shows the ultimate moment capacities of the crossties. The failure mode analysis has been evaluated from crack propagation. It is found that the sleepers with full cross-section and with a vertical hole exhibit a bending mode of failure. We found that there were some snaps of prestressing tendons (tendons reach their characteristic rupture stress) and the first bending cracks can be observed. We can also observe that the sleepers with longitudinal and transverse holes failed by the mixed shear and bending mode.

Table 1. Ultimate moment capacities of concrete crossties with holes and web openings.

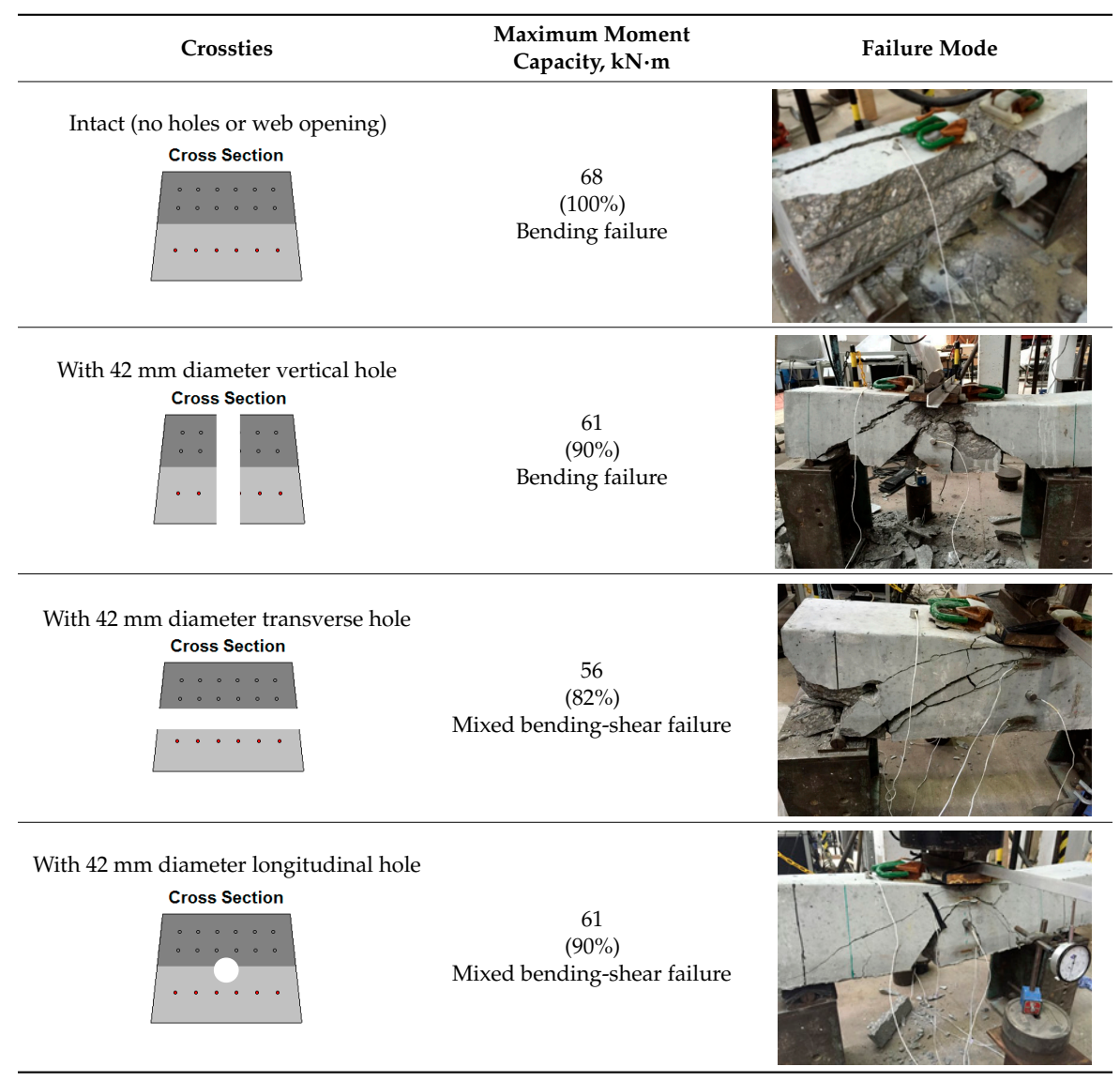


Using load-deflection methodology as illustrated in Figure 4, the toughness of the crossties has been evaluated as shown in Figure 5. The toughness is the area under the load-deflection curve, representing the energy absorption of the structural member. The ductility index (based on displacement ratio) has been derived from the ratio of the maximum displacement over the first yield displacement of crossties $\left(\Delta_{\max } / \Delta_{\mathrm{y}}\right)$. The first yield displacement, $\Delta_{\mathrm{y}}$, corresponds to the intersection of the tangents to the load displacement curve at the origin and ultimate displacement; and the maximum displacement represents the displacement at collapse state (as shown in Figure 3). Therefore, the use of the displacement ductility ratio presents a new criterion in addition to the strength criterion for predicting the early warning capability of railroad crossties. It is evident that holes and web openings generally undermine the maximum strength of concrete crossties. It can be observed that the first cracks developed in the crosstie without holes and those with vertical and longitudinal holes are bending cracks. It is important to note that the crossties failed in a bending related mode. In contrast, it is found that the crosstie with transverse holes failed in the shear mode, and diagonal cracks developed through the hole.

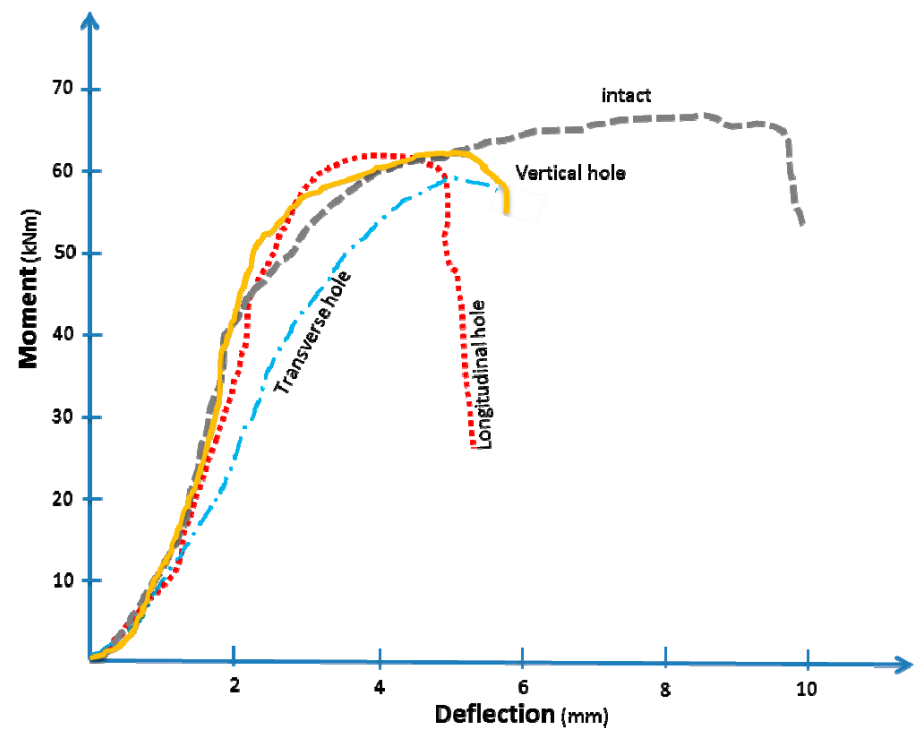

Figure 4. Experimental moment-deflection curves of railroad concrete crossties $\left(0.285 \times 0.175 \times 2.5 \mathrm{~m}^{3}\right)$. Average data was consistently obtained from two specimen tests. The deviation of experimental results is less than $5 \%$. These figures are adopted from [7].

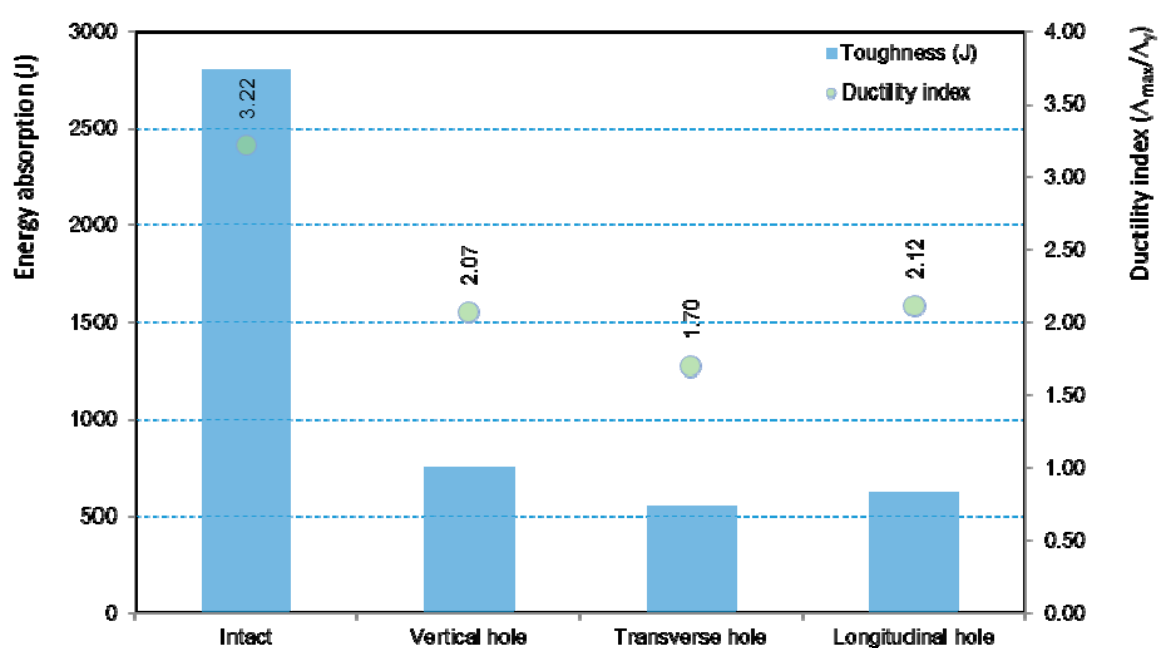

Figure 5. Toughness of railroad concrete crossties with holes and web openings. 
Figure 5 exhibits that the crosstie with transverse holes can absorb the least energy toughness. This also corresponds well with the ductility index results, showing that the crosstie with transverse holes failed suddenly at a brittle shear mode. In addition, it is important to note that the concrete crossties with vertical and transverse holes tend to have relatively lower ductility, resulting in less early warning of structural failure.

\section{Discussion}

In practice, quasi-static design and analysis is adopted in a similar way as testing to simplify the process. At present, the static performance of concrete crossties or sleepers with holes and web openings cannot be realistically estimated [12-15]. This research work is a fundamental step to achieve better insight into the behavior and durability of concrete crossties with holes and web openings. Our experimental results, based on industry practice, reveal that the transverse and longitudinal holes shift the mode of failure from bending to shear-bending. This implies that the application of transverse and longitudinal holes in concrete crossties could affect longer term performance in dynamic conditions, when large deformation of crossties cannot be observed prior to the brittle shear-bending failure mode. Such action will yield very little early warning before structural failure. As a result, it is very important for track engineers to restrict or minimize the use of these holes.

Based on our experimental results, we also found that the strength of materials is very consistent with standard variation of less than 3\%. This significance underpins our confidence in the experimental results with a limited number of samples. However, it is very important to note that we have studied only the cases of industrial practice. Smaller sized holes and web openings ( $<25 \mathrm{~mm}$ diameter) may yield better results. We will investigate this issue further using numerical simulations in the future, in order to evaluate the size effect and the crosstie behavior under impact loadings. Using the finite element method, a three-dimensional model for crossties with different cases of holes and web openings has been calibrated by experimental results from this study [16-22]. The numerical study will enable virtual tests of the crossties with holes and web openings under different limit states (i.e., dynamic and impact conditions due to accidental loading). Our previous work [18] has indicated a relationship between the static and dynamic performance of concrete crossties; it will be further improved to estimate the dynamic capacity of concrete crossties with holes and web openings.

\section{Conclusions}

The holes and web openings undermine the strength, toughness and ductility of railroad concrete crossties. It is essentially important for track and rail engineers to assure that the modification or retrofitting of concrete crossties at construction sites is carried out in a proper manner. Note that existing codes of practice could not accurately estimate such aspects; and they could not portray unforeseen damage or an early warning. From the results obtained in these unprecedented full-scale experiments, it is recommended that transverse holes should be particularly avoided. This is because the transverse hole can reduce almost $20 \%$ of the load bearing capacity of the crosstie and such a hole also results in a significant reduction of energy toughness and importantly ductility. This insight into the structural behavior of the concrete crossties with holes and web openings will enable a safer built environment in railway corridors, especially for concrete crossties whose structural inspection is very difficult in practice. Future work includes testing of the dynamic type to evaluate cyclic test behaviors of railway concrete sleepers and to help improve the dynamic finite element modeling outcomes.

Acknowledgments: The authors would also like to thank British Department of Transport (DfT) for Transport Technology Research Innovations Grant Scheme, Project No. RCS15/0233; and the BRIDGE Grant (provided by University of Birmingham and the University of Illinois at Urbana Champaign). The second author gratefully acknowledges the Japan Society for the Promotion of Science (JSPS) for his JSPS Invitation Research Fellowship (Long-term), Grant No L15701, at Track Dynamics Laboratory, Railway Technical Research Institute and at Concrete Laboratory, the University of Tokyo, Tokyo, Japan. The authors are sincerely grateful to the European Commission for the financial sponsorship of the H2020-RISE Project No. 691135 "RISEN: Rail Infrastructure 
Systems Engineering Network", which enables a global research network that tackles the grand challenge of railway infrastructure resilience and advanced sensing in extreme environments (www.risen2rail.eu).

Author Contributions: Erosha Gamage and Sakdirat Kaewunruen conceived and designed the experiments; Erosha Gamage and Sakdirat Kaewunruen performed the experiments; Erosha Gamage and Sakdirat Kaewunruen analyzed the data; Alex Remennikov and Tetsuya Ishida contributed reagents/materials/analysis tools; everyone wrote the paper.

Conflicts of Interest: The authors declare no conflict of interest. The founding sponsors had no role in the design of the study; in the collection, analyses, or interpretation of data; in the writing of the manuscript, and in the decision to publish the results.

\section{References}

1. Remennikov, A.M.; Kaewunruen, S. A review on loading conditions for railway track structures due to wheel and rail vertical interactions. Struct. Eng. Health Monit. 2008, 15, 207-234. [CrossRef]

2. Remennikov, A.M.; Murray, M.H.; Kaewunruen, S. Conversion of AS1085.14 for railway prestressed concrete sleeper to limit states design format. In Proceedings of the AusRAIL PLUS 2007 Conference \& Exhibition, Sydney, Australia, 2-6 December 2007.

3. Remennikov, A.M.; Murray, M.H.; Kaewunruen, S. Reliability based conversion of a structural design code for prestressed concrete sleepers. Proc. Inst. Mech. Eng. Part F J. Rail Rapid Transit. 2012, 226, 155-173. [CrossRef]

4. Esveld, C. Modern Railway Track; MRT-Productions: Zaltbommel, The Netherland, 2001.

5. British Standard, Railway applications. Track. Concrete Sleepers and Bearers. Prestressed Monoblock Sleepers; British Standards Institution: London, UK, 2009.

6. Fryba, L. Dynamics of Railway Bridges; Thomas Telford Ltd.: London, UK, 1996.

7. Gamage, E.; Kaewunruen, S.; Remennikov, A.M. Design of holes and web openings in railway prestressed concrete sleepers. In Proceedings of the Railway Engineering Conference, Edinburgh, UK, 28 June-July 2015.

8. Kaewunruen, S.; Remennikov, A.M. Progressive failure of prestressed concrete sleepers under multiple high-intensity impact loads. Eng. Struct. 2007, 31, 2460-2473. [CrossRef]

9. Kaewunruen, S.; Remennikov, A.M. Dynamic crack propagations of prestressed concrete sleepers in railway track systems subjected to severe impact loads. J. Struct. Eng. 2010, 136, 749-754. [CrossRef]

10. Pfeil, H. Rail Seat Abrasion in Concrete Sleepered Track; Technical Report No. TR-016; NSW: RSA Technical Services, RailCorp: Sydney, Australia, 1997.

11. Kaewunruen, S.; Remennikov, A.M. On the residual energy toughness of prestressed concrete sleepers in railway track structures subjected to repeated impact loads. Electron. J. Struct. Eng. 2013, 13, 41-61.

12. Vu, M.; Kaewunruen, S.; Attard, M. Nonlinear 3D Finite Element Modeling for Structural Failure Analysis of Concrete Bearers at a Railway Urban Turnout Diamond; Elsevier: Amsterdam, The Netherlands, 2015.

13. Kaewunruen, S.; Remennikov, A.M. Experimental simulation of the railway ballast by resilient materials and its verification by modal testing. Exp. Tech. 2008, 32, 29-35. [CrossRef]

14. Kaewunruen, S. Monitoring structural deterioration of railway turnout systems via dynamic wheel/rail interaction. Case Stud. Nondestruct. Test. Eval. 2014, 1, 19-24. [CrossRef]

15. Rahrovani, S. Structural Reliability and Identification with Stochastic Simulation: Application to Railway Mechanics. Ph.D. Thesis, Department of Applied Mechanics, Chalmers University of Technology, Gothenburg, Sweden, 2016.

16. Kaewunruen, S.; Gamage, E.K.; Remennikov, A.M. Structural behaviours of railway prestressed concrete sleepers (crossties) with hole and web openings. Procedia Eng. 2016, 161, 1247-1253. [CrossRef]

17. Kaewunruen, S.; Gamage, E.K.; Remennikov, A.M. Modelling railway prestressed concrete sleepers (crossties) with hole and web openings. Procedia Eng. 2016, 161, 1240-1246. [CrossRef]

18. Kaewunruen, S.; Remennikov, A.M. Impact capacity of railway prestressed concrete sleepers. Eng. Fail. Anal. 2009, 16, 1520-1532. [CrossRef]

19. Rezaie, F.; Bayat, M.A.; Farnam, S.M. Sensitivity analysis of pre-stressed concrete sleepers for longitudinal crack prorogation effective factors. Eng. Fail. Anal. 2016, 66, 385-397. [CrossRef]

20. Chen, Z.; Andrawes, B.; Edwards, J.R. Finite element modelling and field validation of prestressed concrete sleepers and fastening systems. Struct. Infrastruct. Eng. 2016, 12, 631-646. [CrossRef] 
21. Kaewunruen, S.; Ishida, M. Field monitoring of rail squats using 3D ultrasonic mapping technique. J. Can. Inst. Nondestruct. Eval. 2014, 35, 5-11.

22. Kaewunruen, S.; Remennikov, A.M. Rotational capacity of railway prestressed concrete sleeper under static hogging moment. In Proceedings of the 10th East Asia-Pacific Conference on Structural Engineering and Construction, Bangkok, Thailand, 3-5 August 2006.

(c) 2017 by the authors; licensee MDPI, Basel, Switzerland. This article is an open access article distributed under the terms and conditions of the Creative Commons Attribution (CC-BY) license (http://creativecommons.org/licenses/by/4.0/). 